\title{
Computer Augmented Research and Scientific Misconduct
}

\author{
Wolfgang Coy \\ Humboldt-Universität zu Berlin coy@informatik.hu-berlin.de
}

\begin{abstract}
Internet and CD-ROMs are now important sources of scientific research. Obviously, these computerized tools complement and supplement libraries. For some they seem to replace libraries, and Web presentations of published works are used as seemingly infinite resource of texts for term papers, examination work and even research papers. There is evidence that the use of modern information technology, especially the Internet and CD-ROMs, boosts questionable or even illegal forms of scientific publication. The spectrum of scientific misconduct is broadened by their easily accessible repertoire of research material up to the spread of falsified degrees. This process could be and should be countered by (self-)regulations, technical means, and, most important, education in order keep science as a public process alive.
\end{abstract}

Key words: scientific community, scientific research, science education, plagiarism, falsification, fraud, degree mills, scientific ethics, Internet

\section{CHANGING THE "KNOWLEDGE ORDER"}

The following remarks center on public scientific research and education. It is not about other kinds of research from the very private investigation of the amateur to company research or military research, or to some fundamentalist ways to acquire higher knowledge.

\subsection{The Internet as an agent of change in research}

Within ten years the Internet became an important tool for scientific research and education. The World Wide Web was introduced around 1990 as a mean to distribute "gray" literature, i.e. scientific literature that was 
electronically accessible but not necessarily published in a formal way. This of course reflected an enormous acceleration of the flow of technical information in all fields of research. Globally networked hypertext was a welcome answer to this demand. Very sudden not only preprint servers, but also refereed electronic magazines and books were available in the net, side by side with all kind of informational offers - from well-founded insights to written junk. This development is shared by an overwhelming offer of serious and less serious CD-Rom publications: "Information at your fingertips".

As a practical result to writers citation has become a "click\&paste" experience, including self-citation, generating a plethora of variants demonstrating work, and sometimes stagnation, "in progress". Unfortunately, it is difficult to cite Web-information, as the average life span of a Web page seems to be less than 80 days [Wayback01]. Clearly this might be overcome by precise citation rules and by building Web archives in public libraries or by Google's archive or more other dedicated efforts like the Internet archive project Wayback [Wayback01].

But the Web demonstrates also a dark side of "information at your fingertips", when it supports a loser contact to established citation practices. This is a process that is primarily visible in term papers and examination papers, where scientific writing is demanded from beginners, sometimes demonstrating lose morals towards intellectual property. This problem is the center of the following remarks that unfortunately seems not to be restricted to beginners. It seems to be a push-phenomenon: As the possibilities of anonymous access to a worldwide supply of high-quality written materials are multiplied a growing pull for illegal copies is observed. In colleges it is reported that about 1 of 6 term papers are partially or fully plagiarized [Standler00], in a German Fachhochschule (University of Applied Sciences) an even higher number of misconduct has been identified without general statistical evidence [Weber-Wulf02]. This clearly demonstrates that the problem of plagiarism using the Internet is already reaching into the universities. Though this is not only an outcome of the modern information technology [cp. Broad\&Wade82, Gardner81], it seems to be pushed by the enormous possibilities of the Internet [Martin92, LaFollette92, ORI98, Standler00]. There is yet no hard statistical evidence, and the level of awareness raised in the last decade, but alone the growing number of Websites offering examination papers from school to university levels and the number of cases reported by colleagues supports the view that correct citation and recognition of other's work are in danger. Even grant 
applications and scientific publications in proceedings and journals are subject to such misbehaviour. ${ }^{2}$

\subsection{Scientific research as a public challenge}

Certainly, citation is only a secondary virtue deeply rooted in the formation of scientific societies. It is only a secondary, derived virtue, because it expresses respect for truth and respect for the work and achievements of others. Honestly and adequately admitting what has been perceived and received from the thoughts, the teaching, and the example of others is a rather difficult process; correct citation of the published works or the support of others is only one aspect of this general attitude of scientific collaboration, but there is still a general understanding that this is good scientific practice. The illegal copy of someone's writings or thoughts may be considered at a first glance as a legal conflict between the forger and the author. Then copyright law, or in some cases patent law, or related laws like those regulating trademarks could be applied. This is not without some peculiarities that will be discussed later, but it is also insufficient as science is regulated in modern societies by special rights and duties.

Modern public scientific research is founded on historically developed methodological considerations and implicit ethical regulations that constitute the scientific community. These implicit policies are under attack with recently developed technologies of information storage, distribution, and acquisition, especially with the Internet. In some cases even explicit laws or contracts are violated. It is obvious that science as a part of society depends on that context - in good and in bad. Scientists are probably as human as others and though they may be better educated in some sense, they do not necessarily show better morals than people in comparable subsystems in society. In short, despite high standards in integrity that are a necessary operational fundament of "truth seekers", misconduct is not completely unknown in scientific research. As the evaluation of science and researchers is dominated by examinations and the evaluation of published material, we will concentrate on these aspects - which does not mean that no other unpleasant professional behaviour like mobbing, malicious gossip or

2 I was confronted recently with an application for a research grant to the National German Research Foundation (DFG) that was directly copied from someone else's application. As there are only very few competent peer researchers to evaluate such a report, it happened that the author of the original successful application received the copied one. I should add that it was not in the field of computer science, but this is only a cold comfort. 
defamation exists - but these are common to all large organizations and bureaucracies. We may consider three types of misconduct in scientific publishing:

- plagiarism

- falsification or fabrication of data, and

- fraud.

Unfortunately these types of misconduct seem to spread with the possibilities of global public computer networks, the Internet, and the rapid growth of published material in electronically accessible forms via CDROMs or DVDs. In addition to the still somewhat cumbersome and risky process to "write" papers from uncited sources, to support hypothesis by faked or straightened data, or simply to copy other's materials, there is a new wave of granting dubious or simply faked diploma and awards via so-called "diploma mills" or "degree mills" in the Internet. Sometimes these bogus institutions are disguised as "distance education", but many are simply mail order houses for forged documents. This is not a fun business as it continues with job applications. Recently, Doris Hisey reported: „Surveys by Certified Reference Checking Co. in St. Louis MO report that resume fraud increased $24 \%$ from 1979 to 1999 , with $36 \%$ of applications including falsehoods, and recent statistics show even larger numbers. ${ }^{\text {"3 }}$

\subsection{Plagiarism and intellectual property rights}

Plagiarism is by itself in most states no criminal offence, but it may legally be subject civil law. As the scientific value system is international, it is obvious that scientific misconduct cannot be judged by national law alone. There may be at least two different aspects of scientific plagiarism:

a) infringement of copyright laws or droit d'auteurs (i.e. rights of the author in continental European tradition), and

b) theft of ideas, which may or may be not, a violation of patent law.

Copyright law regulates use and sale of a shaped artefact like a text, an image, a film, or a program for the use of the buyer. Even though the buyer may be free to use this artefact without the necessity to expressively claim the fact that someone else produced it, he or she may not claim authorship. In the continental European tradition of the droit d'auteur authorship can never be sold; it is an inseparable "eternal" right of the author. But the right to commercialise that intellectual artefact may be granted for some period, which makes copyright and droit d'auteur compatible in many practical 
aspects. In any case correct credit must always be given - usually by correctly citing the author. ${ }^{4}$

There is no copyright or droit d'auteur to an idea, leaving the grey zone of adaptation or paraphrasing. But as one may not simply make a movie out of a book, one may not simply rewrite or paraphrase someone else's text. But, at least in literature, poetry, theatre or cinema, it seems to be perfectly agreeable to copy the basic idea of a story. Otherwise "boy meets girl" would have been restricted to a single movie.

The concept of plagiarism of ideas is different in science, but merely by cultural convention. Only patent law deals with ideas, but this is restricted to technical and industrial constructions or processes (with certain national peculiarities, e.g. patents for software). Depending on the special field, patent law may be applied to scientific plagiarism - usually restricted by a focus on machines and industrial commercialisation. In addition to copyright and patent law other rights may be violated, e.g. trademark regulations, or as pointed out in [Standler00] "law on unfair competition". But this varies in different nations or states.

So plagiarism of ideas alone is probably not illegal, but is considered bad practice in science. Under all circumstances, it is expected that a particular idea is attributed to its author unless he or she is unknown or the idea has reached the status of common knowledge. The enforcement of these rules is left to educational institutes, editors or examiners. As a scientific attitude it is left to education.

\subsection{Modern society and its knowledge order}

The success of modern societies in succession of the great revolutions in England, the United States, and France, depends heavily on law, regulation of politics, and economy. In the tradition of the French revolution this would be the constitution, the code pénal and the code civil. But some fields of society are under special regulations, e.g. religion, education, and research. Following Helmut Spinner, we call the regulations of the latter two "Knowledge Order". Public education is a form part of this knowledge order. Public libraries, copyright rules or the special rules regulating scientific research are other aspects of this order that sometimes may be in contrast to other political or economical regulations.

4 Intellectual property rights are used differently in different social contexts. No politician will be acclaimed of plagiarism when using the text of a "ghost-writers" - though we usually can judge the non-authorship of some phrases or ideas [Martin94]. This may lead to conflicts in the case of science politics. 
The Prussian university reform from 1809 followed the concepts of Wilhelm v. Humboldt with a declaration of independence of scientific research from politics and economy. In order to give space for productive research and education within the limits of a Prussian monarchy, science was declared as public task. Scientific thought should no longer be hindered by the church or the state - in contrast to a firm suppression of other forms of free speech in Prussia. Results of scientific research should be published and. given freely to the public. In return university researchers were paid by the state - serving as scientists and as educators. This was Humboldt's "unity of research and education." Commercial exploitations of scientific insights were considered to be in the public domain - only respecting the immaterial rights of authorship. Humboldt's concept served as a widely recognized model, but it was soon introduced to the realities of an emerging industrialism. As more scientific findings were commercially relevant their public use was restricted by patent laws and other rules, while scientific research was to a growing extent paid from the outside or performed in closed industrial, military or otherwise funded environments.

Despite this complex situation the scientific communities ${ }^{5}$ are well aware of the advantages that open exchange of ideas and findings establishes. This lead to an mostly implicit system of rules of scientific conduct, including a serious dedication to "truth" with respect to research methods and the technical interpretation of findings, and a high appraisal for authorship and the special recognition of the "first" who found some specific result. Practically these implicit rules led to a complex setting of peer review, necessity of correct citation, plagiarism as misbehaviour, demand for correct descriptions of data and facts, and a strong disapproval of all kinds of scientific fraud.

\section{PLAGIARISM AND FRAUD IN TIMES OF THE INTERNET}

\subsection{Plagiarism from school to scientific journals}

Probably schoolboys and schoolgirls minimized their homework by copying as long as homework exists. But a look into the World Wide Web demonstrates that computer literacy and especially the knowledge of the Internet increases the possibilities in many ways. There is a large number of term papers stored as so called "research papers" in any language and in any

5 a plural that is due to specialisations that formed different research "cultures" [cp.

C.P.Snow [Snow59] or, more recently J. Labinger and H. Collins [Labinger\&Collins01]) 
field. It is quite understandable that someone who really spent a lot of effort in such a paper is proud to demonstrate his or her authorship and wants a large number of readers - after all that is what authorship is usually all about. But the situation is critical when these papers are sold and are put into a context where cheating is implied: "Pay and present it to your teacher in the next morning". In some college classes and comparable schools there are estimates that about every sixth paper is forged - very often by copying from the Internet. The Internet adds two elements to this straight form of plagiarism: The net makes overwhelming offers to a searching soul, and it is to a large extend anonymous (The net's basic flaw, namely a complete lack of context is typically not evident to the betrayer). It is a typical "push" situation. We must assume that undetected forgery is considered as an invitation to repeat such fraudulent behaviour in the later career - at the university as well as in the job.

Though there is a gray zone about the actual figures, the figures seem to rise - but rising figures may also be caused by better awareness of teachers. Two aspects in this development are remarkable:

a) many plagiarists do not feel guilty; they consider their behaviour as clever and acceptable, though they usually know that it would be better to write something on their own, and

b) they do not know that other's writings can be correctly cited, and by that way introduced in their own work.

While plagiarism in school may be seen as an unwanted but unavoidable technical modernization of an already established behaviour, it is unacceptable in the research environment of universities. But plagiarism is present in college or university classes, which demonstrates that the assumed idea of a teacher or scientist as a role model does not work well under the conditions of mass universities. This, of course, calls for appropriate action.

Another excuse sometimes heard is that nobody is victim of the act of plagiarism, once the original author puts it on some "homework Web site" or even sells it to the plagiarist. In fact a legal judgement of plagiarism is difficult, as we saw. It should be noted however that plagiarism turns into fraud, when it is used to get a grant, a scholarship, or a scientific position.

A rather funny way of plagiarism is it's technical opposite. It is reported that some candidates were so impressed by their teacher's demand for correct citation that they forged evidence by citing non-existing sources. "As Jones has shown in [Jones 1997, p. 12] the earth is nothing but a flat disk..." Of course, the forgery may easily be detected. But it is no longer a simple case once the Internet is brought in: "As Jones has proved in http://www.flatworlds.org the earth is a flat disk..." 


\subsection{Falsification and fraud}

It is really difficult to fake a mathematical proof, but it is relatively easy to alter or even invent experimental data to support some controversial, but not too controversial hypothesis. Therefore falsification is primarily a subject of experimental sciences. As a consequence a series of falsified papers has been detected on medical and biological research, not only in the USA [ORI98], but also in other countries [Mayntz99]. This even lead to the forming of an U.S. Office for Research Integrity whose primary job is to survey the misuse of grants given by the U.S. Dept. of Health and Human Sciences. But there is no question that falsified or "corrected" data sometimes find their way to engineering, chemical, or physics journals.

"Correcting" data, selecting some and dropping others is an elegant way to shorten research and to strengthen results. It is a dark spot in experimental sciences, as there is no rule when to start or to stop collecting data. As things are unavoidably "going wrong" sometimes in experimental laboratory setups, it is completely understandable that some data may be considered unusable - sometimes. It is good practice to report all data, including those later to be excluded, but it is not possible to include all experimental results in the limited space of a publication - allowing falsification. Gardner [Gardner81] pointed out the case of Gregor Mendel, the Moravian monk that detected the laws of transmission for pea blossom colors in the $19^{\text {th }}$ century, a field now called genetics. There is hard statistical evidence that Menzel beautified his findings - probably only to convince himself of his exciting, and basically undisputed law.

Who is victim of such abbreviations to truth? No direct harm is done and, as long as the result is correct, this is even an acceleration of scientific advancement. Unfortunately there are many victims. The result may be wrong, leading other research in the wrong direction. But even, if the forger's intuition is right, it is a question of scientific standards, and of reliabilty. How reliable is someone's "intuition"? And consider that someone else is working on the same experiment with the same intuition, but collecting data in a more decent way. Then who was the first to receive the experimental result. As scientific rewards depend so strictly on these "firsts", manipulation of data is a serious misbehaviour.

The notion of fraud is usually avoided in science - misconduct or misbehaviour sounds much better. But blatant fraud exists and number of cases was brought to the public attention in the last years. But despite public attention, detected scientific fraud is a rare case ${ }^{6}$. Even undetected fraud may be relatively rare, because today's science is a collective and highly

${ }^{6} \mathrm{cp}$. figures in [ORI98] 
competitive endeavour. There is also a gap between the everyday notion of fraud that describe a rude and dishonest attitude and the more specific legal definition of fraud that varies in the specific national laws. As a rule of thumb we may assume that fraud depends on a) a treacherous behaviour, especially willingly and knowingly hiding or stating as a fact something important that is false or untrue, b) with the intention to make someone act relying on this fact, c) so that an injury or damage results or may result for the misinformed party. In the case of academic fraud, the scientific community is not very critical about c), and a) is extended to the point that stating something as fact that is not investigated and proved constitutes also scientific misbehaviour.

Under many national laws fraud is criminal offence. In German law fraud is restricted to cases where property is gained illegally (StGB §263 Betrug, $\$ 266$ Untreue; German penal code). From the Aberdeen College "Prevention of Fraud"-Brochure that the notion fraud is used in the UK in a much broader, but also quite vague sense: "No precise legal definition of fraud exists; various Acts of Parliament cover many of the offences referred to as fraud. The term is used to describe such acts as deception, bribery, forgery, extortion, corruption, theft, conspiracy, embezzlement, misappropriation, false representation, concealment of material facts and collusion." To meet the intention of good scientific practice, Aberdeen College proposes: "For practical purposes fraud may be defined as the use of deception with the intention of obtaining an advantage, avoiding an obligation or causing loss to another party." The Canadian University of Ottawa defines fraud in its academic environment as:

"Academic fraud is an act by a student which may result in a false academic evaluation of that student or of another student. Without limiting the generality of this definition, academic fraud occurs when a student commits any of the following offences:

a) Commits plagiarism or cheating of any kind.

b) Submits a work of which the student is not the author, in whole or in part (except for duly cited quotations or references). Such work may include an academic paper, an essay, a test, an exam, a research report, and a thesis, whether written, oral, or in another form.

c) Presents research data which has been falsified or concocted in any way.

d) Attributes a purported statement of fact or reference to a source which has been concocted.

e) Submits the same piece of work or a significant part thereof for more than one course, or a thesis or other work which has already been submitted elsewhere, without written authorization of the professors concerned and/or of the academic unit concerned. 
f) Falsifies an academic evaluation, misrepresents an academic evaluation, uses a forged or falsified academic record or supporting document, or facilitates the use of a falsified academic record or supporting document.

Undertakes any other action for the purpose of falsifying an academic evaluation." [UoOttawa02]

Obviously, the international scientific communities can not rely only on the regional law, but must find a mutual understanding of academic fraud within the scientific societies.

\subsection{A special case of fraud}

Any reader of crime stories or political debates knows the basic tactic of investigation: "Follow the money!" In fact, a number of fraudulent behaviour stands under the pressure of "Publish or perish!" A tenure professorship in my university is assumed to generate a total cost over the working period around of 7-9 Mio. Euro. A scientific testimonial in court may be worth even more to some interested party, e.g. tobacco industry, builders of nuclear power plants, or even in case of a simple industrial accident. These are obvious motives for scientific fraud and lesser misconduct.

But there are some cases where simply the desire to impress or the pressure to deliver may cause falsification or fraud. This is another side of "Publish or perish!" And then exists a seemingly unselfish type of fraud the hoax. There is an ongoing debate on Alan Sokal's paper submitted to and printed by the once respectable journal Social Text [Soka196]. It provoked a heated debate on the values and methods of some post-modern theorists. As we cannot assume that the theoretical physicist Sokal wanted to start a second career in cultural studies or in philosophy, we cannot interpret his article as genuine fraud. Sokal made a hoax to clarify the borders between serious research and pretended, but misappropriated knowledge. How far this is good scientific practice is left to the reader.

\subsection{Diploma Mills and Title selling}

"What means robbing a bank compared to the founding of a bank?" Even if a singular scientist is guilty of fraud, his or her damage to science and education means nothing against a estimated 200 Mio $\$$ business that commits fraud on an everyday basis by generating annually thousands of false degrees from bachelor to doctorate annually [Bear99]. Clearly, such Degree Mills commit and support fraud as an obvious criminal act. Strange enough there is no simple global solution to end the existence of these false 
universities and schools. Too many cultural and historical peculiarities shaped national education. Conflicting understandings of the role of education, religion and rights of freedom (of speech, of teaching, of religion...) allow new schools and even universities to be founded everywhere. Distance education and the further commercialisation of teaching, both important cornerstones of concepts of Life Ling Learning will make the situation even worse.

Not all states show a strict surveillance of their educational institutions. Probably only international treaties may lead to lists of acceptable practices and transparent accreditation. But even in these cases awareness is necessary from officials, teachers, scientists, or employers.

Several years ago German TV reported of a Cologne pharmacist who collected 17 doctorates around the world, none of which was admittedly earned by a serious research thesis and none of which he may use legally in Germany. While we may smile at vanity of a such a collector, a warning voice from Singapore (http://homel.pacific.net.sg/ chriosyeh.degmill.htm) reminds us that many people worldwide see their chance in getting some kind of degree and by spending all their money unknowingly to some fake distance learning institution like the now closed Columbia State University that advertised in papers from the Economist to USA Today: "University Degree in 27 Days! Bachelor's, Mater's, Doctorate..." [Bear99]

Expensive paper ads are not longer necessary. The Internet has become a first-class advertising medium for these swindlers and business grows truly global. As distance education and life-long learning becomes more and more important, it becomes necessary to build a global system of reliable accrediting agencies and make their value visible to all interested parties.

\section{COUNTERMEASURES}

Scientific research is an open process with great value to its members, but also to societies. It has clear advantages over privately and covert research that hinder distribution of knowledge and education, weakening the process of general welfare. In order to keep these achievements alive, science should be understood as an open source process. The very basis of this process lies in unrestricted publishing of new findings. As the scientific community is primarily rewarded indirectly by recognition of merits via publishing, correct citation and the prevention of plagiarism or the publication of falsified or fabricated results is of prime interest to the community. If there is such general value attributed to science, one may ask: Why do students or scientist weaken this system by committing plagiarism, falsification, or fraud? Why do people try claim degrees they did not earn? It 
is probably, because they live in societies where scientific and educational achievements are regarded high, where they are lucrative, and where cheating and fraud is considered as some not necessarily decent, but possible behaviour. Science and education form an important subsystem of society and we can therefore not expect them to be completely different from its other parts.

The crucial question is: How can society keep control over research and education processes? Is there a democratic and self-regulating solution inside science and education or should society counter attacks to reliable and open scientific practice by stricter laws?

\subsection{Laws and self-regulations}

There are several possibilities where to regulate honest academic behaviour. The strictest form would be national law with international agreements. Many scientists may consider such legislation as to much overhead and too strict interference. It will also be difficult for law enforcement to cope with the different grown cultures in specific sciences. The idea of correct citation alone is quite different in humanities, in law, or in engineering studies. Many other subtle differences may be found.

Universities may be encouraged to state policies of honest and good practice for their students. They may go further and issue guidelines for their faculties in order to keep scientific research a common public endeavour, but probably scientific societies, national and international, are the best place to formulate such policies. Of course there are additional regulatory solutions if national or international laws governing intellectual property are violated. But scientific research and scientific publishing is only rudimentary protected by these laws; hence they have to be complemented by guidelines of good practice or professional ethics ([Berleur\&Brunnstein96], [ACM92], [IEEE90], [GI-Rödiger93]) and by precise claims und agreements within the specific scientific communities. While some communities like the medical profession or architects have comparably strict regulations, others like computer scientists have relatively weak standards, and others like philosophers or art historians have no explicit rules at all.

\subsection{Technical means to detect misconduct}

The illegitimate use of other's texts seems to become a widespread phenomenon, now with heavy use of the Internet [Weber-Wulf 2002]. While direct plagiarism seems to be rather rare among scientific papers ${ }^{7}$ submitted

${ }^{7}$ but $\mathrm{cp}$. the case of Elias A.K. Asabti reported in [Broad\&Wade81] 
for or printed in publication in conferences or journals, but it is a technique of choice for first-time or untrained writers, where the writing itself is felt as dominant barrier. As long as the copied text is already published in the Internet, it is not to difficult to locate it either with a search engine like Goggle.com or the specialised Findsame.com, or by the use of programs like Essay Verification Engine (eve) or Glatt Plagiarism Screening Program (GPSP). This may be more difficult when the text was translated (e.g. by programs like Altavista Babel Fish with minimal smoothing). In such a case a critical search engine check of the cited literature may help an investigating teacher or reviewer.

Technical checks are more or less useless if a proficient writer cites other's results in his or her own style; a technique which was not uncommon in many cases of scientific fraud described by Broad and Wade [Broad\&Wade82]. There are even dimmer perspectives when we consider rule-based programs that reformulates a text on the basis of paragraphs which are well within the present scope of automatic text processing. We may conclude that there are technical answers to primitive forms of plagiarism or sloppiness but they are easily overcome by someone determined to break the rules.

\subsection{Education}

In some reports about plagiarism of term papers a general ignorance of the correct way to cite other's works was stated. This demonstrates that implicit rules that teachers think to have transmitted are not to be taken as granted. Respect for the work and achievements of others and the attitude to admit honestly and adequately what has been perceived and received from their thoughts and writings has to be learned explicitly, and therefore it has to be taught.

Teachers have to accomplish several steps in dealing with honest academic practice:

a) Teachers have to understand the educational process to interpret possible dishonest behavior.

b) Such behavior must be identified and discussed with the suspect.

c) To reduce any attempts of plagiarism or fraud the background of scientific research in its historical dimension and its importance to society has to be taught.

d) Guidelines for correct behavior as well as examples of misbehavior should be discussed.

The scientific community has to develop a mutual understanding of good practice. Policies of scientific societies may help, but it is even more important that whistle-blowing and taking action is accepted and supported. 
Unfortunately there is still a tendency to ignore the possibility of academic fraud and blame those who point to actual irregularities. The problem was reported recently by the German National Research Foundation in their examination of the most serious case of scientific fraud in Germany until now. This report was also cited in Nature [Nature 1998, p.395, 532], where bad cooperation of professional societies was pointed out: "The report places most of the blame for this case of scientific misconduct or standards in clinical research in Germany. In particular, they criticise the fact that clinicians do not have a formal training in research methods and the wellknown problem of scientific careers based only on a extensive publication records. Some of the men of the task force were also critical of the insufficient cooperation by professional societies." (Italics by the author).

As it becomes more and more difficult to teach it implicitly (i.e. by example) in times mass universities, we have to set up explicit policies for good scientific practice, including guidelines for correct treatment of data, correct citation and due respect for intellectual property.

\subsection{The road ahead}

Within each field of research there is a large number of shared values and implicit rules how to preserve these values. Scientific communities were founded more or less as closed groups with special rewards and exclusion rules, but their success was in open and transnational cooperation. Max Weber [Weber19] pointed out in his famous essay from 1919: “"Persönlichkeit' auf wissenschaftlichem Gebiet hat nur der, der rein der Sache dient" Scientific work is not simply a job, it should be considered as vocation - and the duty to develop a scientific personality. Though this attitude may look slightly out of time, it remains in fact the only reason why scientific communities may claim special rules for misconduct like plagiarism, falsification, and fraud.

Obviously such an attitude was always under the pressure of commercial or political interests; this is even worse now under the actual conditions of global accelerated exchange. If scientific communities want to keep the essence of successful scientific collaboration over the borders of interests and nations, the rules of small closed groups, where every member knows most of the other members, have to be transformed into explicit regulations and policies for large collaborating communities interacting in good but also controlled will. Regional and international scientific societies and federations, like ACM, BCS, GI, IEE, IEEE, CEPIS, or IFIP must find ways to establish such policies.

8 "A scientific personality is defined by serving the (scientific) cause." 


\section{REFERENCES:}

[Aberdeen01] Aberdeen College, Prevention of Fraud, Aberdeen, March 2001

[ACM92] ACM Code of Ethics and professional Conduct, http://www.ccsr.cse.dmu.ac.uk/resources/professionalism/codes/acm.html (as of 1.1.2002)

[Bear99] John B. Bear, Diploma Mills, University Business, March 2000 http://www.universitybusiness.com/0003/diploma.mhtml (as of 12.12.2001)

[Bear\&Bear01] John B. Bear, Mariah Bear, Degree Mills, http://www.quackwatch.com/04consumerEducation/dm0.html (as of 1.1.2002)

[Berleur\&Brunnstein96] Jacques Berleur \& Klaus Brunnstein (Eds), Ethics of Computing: Codes, Spaces for Discussion and Law, A Handbook prepared by the IFIP Ethics Task Group, London: Chapman \& Hall, 1996

[Broad\&Wade82] William Broad, Nicholas Wade, Betrug und Täuschung in der Wissenschaft, Basel; Boston; Stuttgart.: Birkhäuser. 1984 (original: W. Broad, N. Wade, Betrayers of the truth - Fraud and Deceit in the Hall of Science, New York: Simon \& Schuster, 1982)

[Coy98] Wolfgang Coy, A Future of Knowlege. In K. Brunnstein, P. Randle, P.P. Sint (eds.), KnowRight '98, Proc. of the XVth IFIP World Computer Congress in Vienna-Budapest, Wien: Schriftenreihe der ÖCG 1998

[IEEE90] IEEE Code of Ethics, http://www.ieee.org/about/whatis/code.html (as of 1.1.2002)

[Gardner81] Martin Gardner; Kabarett der Täuschungen, Berlin; Frankfurt/Main; Wien: Ullstein, 1983 (original: M. Gardner: Science - God, Bad, and Bogus, Buffalo, N.Y.: Prometheus 1981

[Hisey01] Doris Hisey, B.S., M.A., Ph.D. - Really? SI-Review, Nov/Dec 2001

[Labinger\&Collins01] Jay A. Labinger, Harry Collins, The one Culture? A Conversation about Science. Chicago/London: The University of Chicago Press, 2001

[LaFollette92] Marcel C. LaFollette, Assessing the impact of New Technologies On Science Fraud, The Scientist, Vol.6(9):11, April 1992

[LaFollette92a] Marcel C. LaFollette, Stealing into Print: Fraud, Plagiarism, and Misconduct in Scientific Publishing, Univ. of California Press, 1992

[Martin94] Brian Martin, Plagiarism: A misplaced emphasis, Journal of Information Ethics, Vol. 3:2, Fall 1994, pp.36-47, also

http://www.uow.edu.au/arts//sts/bmartin/pubs/94jie.html (as of 1.1.2002)

[Martin92] Brian Martin, Scientific Fraud and the Power Structure of Science, Prometheus, Vol. 10:1, June 1992, pp.83-98, also 
http://www.uow.edu.au/arts//sts/bmartin/pubs/92prom.html (as of 1.1.2002)

[Mayntz99] Renate Mayntz, Betrug in der Wissenschaft - Randerscheinung oder wachsendes Problem?, Köln: Max Planck Institut für Gesellschaftsforschung, MPIfG Working Paper 99/4, April 1999

[ORI98] ORI - Office of Research Integrity of the Office of Public Health and Science, US Dept. of Health and Human Science, Scientific Misconduct Investigations 1993-1997, http://www.ori.gov (as of 1.1.2002)

[GI-Rödiger93], Karl-Heinz Rödiger e.a., Ethische Leitlinien der Gesellschaft für Informatik, Informatik-Spektrum 16 (1993), S. 238-240, (engl. translation: GI - Ethical Guidelines http://www.ccsr.cse.dmu.ac.uk/resources/professionalism/codes/german.html; as of 1.1.2002)

[Snow59] C.P. Snow, The Two Cultures and the Scientific Revolution, New York: Cambridge University Press, 1959

[Sokal96] Alan Sokal, Transgressing the boundaries, Toward a transformative hermeneutics of quantum gravity", Social Text 46/47, 1996, pp.217-252

[Sokal\&Bricmont97] Alan Sokal, Jean Bricmont, Intellectual Impostures, London: Profile Books, 1998 (French Orig. 1997)

[Spinner94] Helmut Spinner, Die Wissenordnung, Opladen: Leske+Budrich, 1994

[Standler00] Ronald B. Standler, Plagiarism in Colleges in USA, http://www.rbs2.com/plag.html (as of 1.1.2002)

[Trocchio95] Federigo di Trocchio, Der große Schwindel - Betrug und Fälschung in der Wissenschaft, Frankfurt/Main-New York: Campus, 1995 - ital. original 1993

[UoOttawa02] Academic Fraud, http://www.uottawa.ca/academic/commonlaw/current students/graduate/regulations/ (as of 29.12.2001)

[Wayback01] The Internet Archive: Building an Internet library, http://www.archive.org/ (as of 1.1.2002)

[Weber-Wulf02] Debora Weber-Wulf, Schummeln mit dem Internet? ct' 1/2002, p.64-69

[Weber19] Max Weber, Wissenschaft als Beruf (Science as Vocation), in: Geistige Arbeit als Beruf, München/Leipzig: Duncker \& Humblot, 1919, p. 3-37 